\title{
STRATEGIES FOR CARDIOPULMONARY EXERCISE TESTING OF PECTUS EXCAVATUM PATIENTS
}

\author{
Moh H. Malek, ${ }^{a}$ Jared W. Coburn ${ }^{\text {b }}$
}

\begin{abstract}
Malek MH, Coburn JW. Strategies for cardiopulmonary exercise testing of pectus excavatum patients. Clinics. 2008;63:245-54.

The purpose of this paper is to provide strategies for cardiopulmonary exercise testing of pectus excavatum patients. Currently, there are no standardized methods for assessing cardiovascular and pulmonary responses in this population; therefore, making comparisons across studies is difficult if not impossible. These strategies are intended for physicians, pulmonary technicians, exercise physiologists, and other healthcare professionals who conduct cardiopulmonary exercise testing on pectus excavatum patients. By using the strategies outlined in this report, comparisons across studies can be made, and the effects of pectus excavatum on cardiopulmonary function can be assessed with greater detail.
\end{abstract}

KEYWORDS: Funnel Chest/diagnosis. Circulatory and Respiratory Physiology. Thoracic Wall/abnormalities.

\section{BACKGROUND}

Pectus excavatum (Figure 1) is a relatively common congenital deformity of the chest wall, with an incidence of approximately one in every 300 to 400 Caucasian male births. ${ }^{1}$ This condition is more common than Down syndrome, which occurs one in every 600 to 1,000 births. ${ }^{2}$ Although the pathogenesis of pectus excavatum remains unclear, investigators have hypothesized that the deformity results from unbalanced overgrowth in the costochondral regions. As a result, the chest appears concave, and a displaced heart is often palpable on the left mid-axillary line slightly below the armpit. Pectus excavatum occurs more often in males than females $(6: 1)$ and accounts for $90 \%$ of congenital chest wall deformities. ${ }^{3,4}$ Approximately $40 \%$ of pectus excavatum patients are aware of one or more members of their family who have pectus deformities; however, a genetic link has not been established. ${ }^{4}$

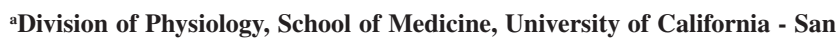
Diego/CA.

'Department of Kinesiology, California State University - Fullerton/CA. mhmalek@ucsd.edu

Received for publication on 26/11/07

Accepted for publication on 29/12/07
The severity of pectus excavatum can be calculated by dividing the inner width of the chest at the widest point (a) by the distance between the posterior surface of the sternum and anterior surface of the spine (b) as determined by computed tomography (CT) scans or chest radiographs (Figure 2). ${ }^{5}$ The normal chest has an index of 2.5, however, in our experience we have observed symptomatic pectus excavatum patients with severity indices ranging from 3.2 to $8.0 .^{6,7}$ It should be noted that older patients often experience more severe symptoms with a lower index than do adolescents. ${ }^{4}$

Recently, Malek and colleagues ${ }^{8-10}$ conducted two meta-analyses examining the effects of surgical repair on cardiovascular and pulmonary function in pectus excavatum patients. The investigators reported that cardiovascular function significantly and clinically improved after surgical repair $(\mathrm{ES}=0.59 ; P<0.05),{ }^{9}$ whereas pulmonary function did not significantly improve after surgical repair $(\mathrm{ES}=$ $0.08 ; P>0.05) .{ }^{10} \mathrm{~A}$ salient finding in the meta-analyses of Malek et al. ${ }^{9,10}$ was the fact that many studies did not utilize a standardized method of determining cardiovascular function, pectus severity index, or control for potentially confounding variables, such as the subject's habitual physical activity level preoperatively and postoperatively. Based on the results of Malek et al..$^{9,10}$ and our experience ${ }^{6,7}$ with pectus excavatum patients, it is our position that specific 

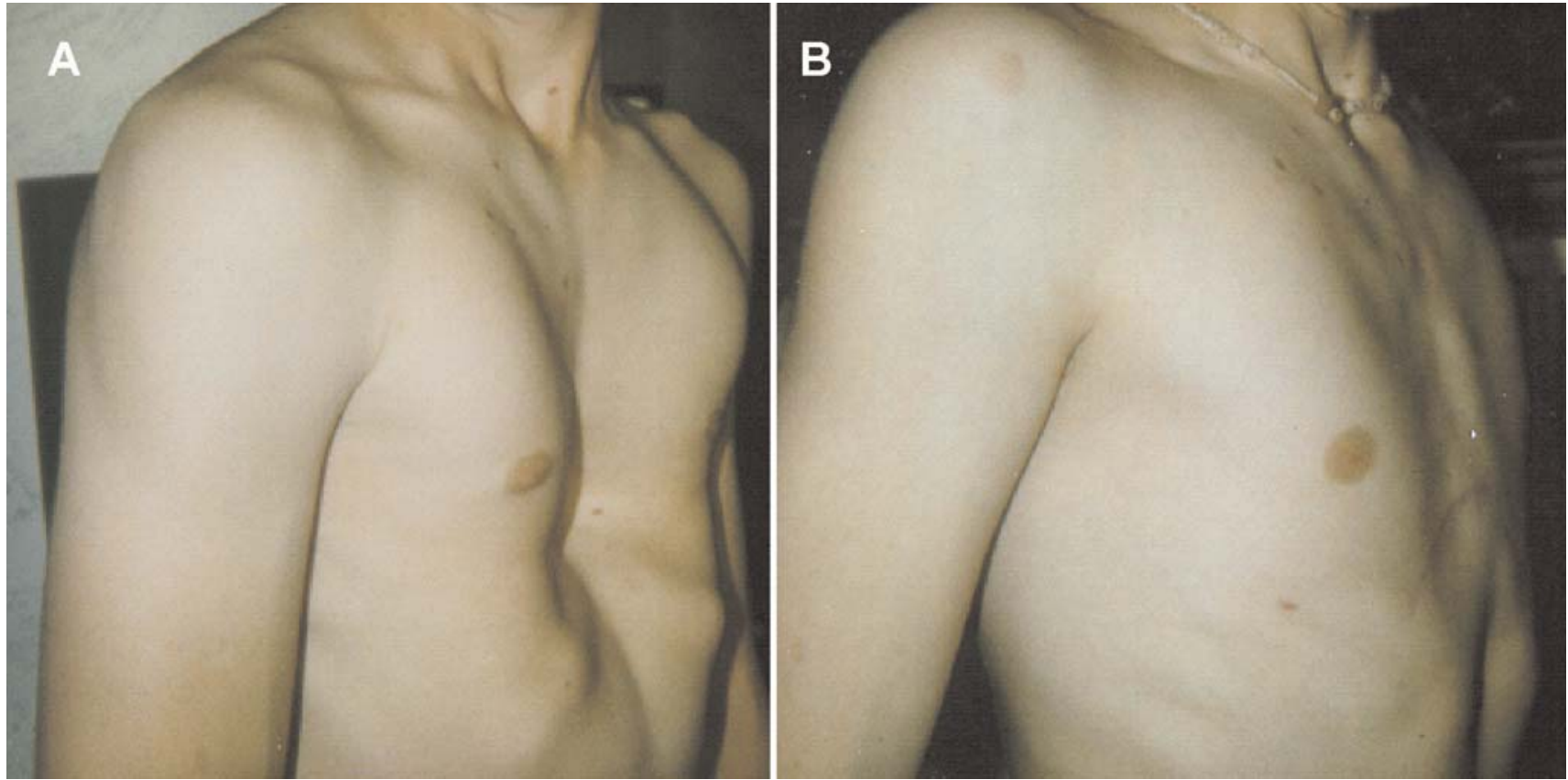

Figure 1 - Depiction of patient with pectus excavatum before (A) and after (B) surgical repair using the Highly Modified Ravitch Repair (HMRR) $)^{59}$

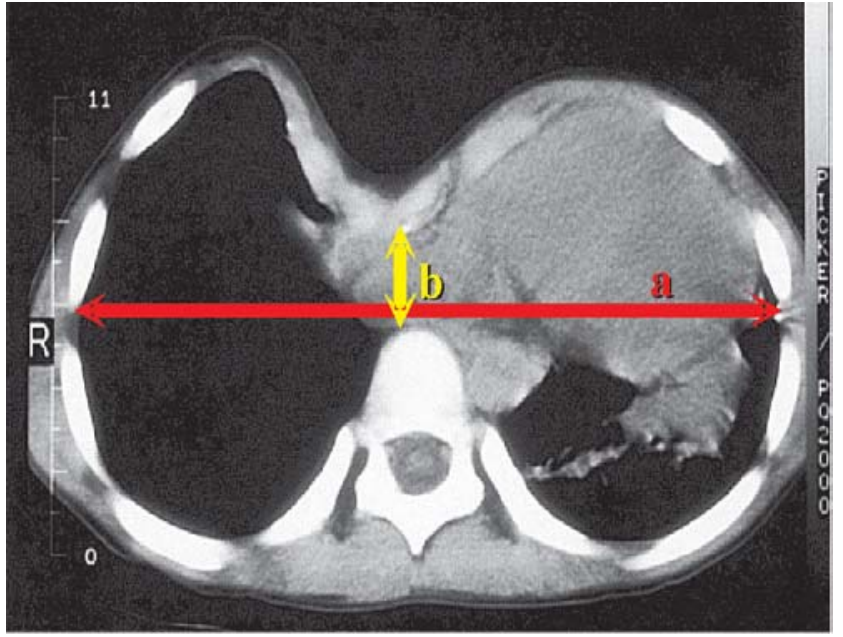

Figure 2 - Measurement of the pectus severity index using a CT scan. This is calculated by dividing the inner width of the chest at the widest point (a) by the distance between the posterior surface of the sternum and anterior surface of the spine (b)

strategies related to assessing cardiopulmonary function in pectus excavatum patients is warranted in order to more effectively compare results between studies without employing a meta-analytic approach. Although there are two textbooks ${ }^{11,12}$ and one paper ${ }^{13}$ on exercise testing and interpretation, they are not specific to pectus excavatum patients and do not provide step-by-step strategies for performing cardiopulmonary exercise testing (CPET). Therefore, the purpose of this paper is to provide specific strategies for examining cardiopulmonary function in pectus excavatum patients.
Introduction to Cardiopulmonary Testing (CPET)

There are various invasive and noninvasive methods of assessing cardiovascular and ventilatory function, however, the use of CPET allows examination of the integrative responses of the cardiovascular and ventilatory response to maximal incremental exercise. ${ }^{11-13}$ CPET is an invaluable assessment tool used to 1) classify individuals for health risk, 2) quantify training intensity for aerobic exercise prescription, and 3) monitor the effects of aerobic training programs in healthy and clinical populations ${ }^{13-15}$. Although other assessment techniques such as electrocardiograph, questionnaires, and/or submaximal exercise protocols have been used to estimate exercise tolerance, Meyers ${ }^{16}$ stated, “... measurements of ventilation and gas exchange responses... [are] the only modality that provides an accurate and objective expression of exercise capacity." (p.S49). CPET can be performed using different modes of exercise that include the treadmill, ${ }^{17}$ arm ergometry, ${ }^{18}$ single-leg knee extension ergometry, ${ }^{19,20}$ or cycle ergometry. ${ }^{7}$ Although each mode has associated advantages and disadvantages, it is our position that studies examining cardiopulmonary function in pectus excavatum patients should use cycle ergometry. Cycle ergometry provides a number of advantages over the other modes of exercise testing: 1) subject comfort, 2) reduction of potential joint injuries associated with weight-bearing exercise, 3) control of cadence, and 4) researcher control of the external work rate. ${ }^{12,13}$ This last feature is particularly important since small increments in work rate over the duration of the test will allow for detection of subtle changes in 
cardiovascular and ventilatory function, which may provide insight into the patient's exercise tolerance.

\section{Exercise Physiology of CPET}

As shown in Figure 3, one of the primary components used to describe cardiopulmonary function is oxygen uptake $\left(\mathrm{S}_{2}\right)$ which is represented by the Fick equation where $Q^{s}$ is cardiac output and $\mathrm{C}_{(a-\bar{v})} \mathrm{O}_{2}$ is the difference between the oxygen content of the arterial $\left(\approx 20 \mathrm{ml}\right.$ of $\mathrm{O}_{2} \mathrm{ml} \mathrm{O}_{2} \cdot 100 \mathrm{ml}^{-1}$ of blood) and venous sides (varies with exercise intensity). Cardiac output, however, is a product of $f_{c}$ (cardiac frequency) and stroke volume (SV). Stroke volume can be further decomposed to end-diastolic volume (EDV) and end-systolic volume (ESV). During incremental cycle ergometry, $S V$ increases to a percentage of $\mathrm{VO}_{2}$ max and plateaus, ${ }^{21}$ whereas $f_{c}$ continues to increase and may eventually plateau at ${ }^{S} \mathrm{O}_{2}$ max. The $\mathrm{C}_{(a-\bar{v})} \mathrm{O}_{2}$ gradient during rest is approximately $4 \mathrm{ml}$ $\mathrm{O}_{2} \cdot 100 \mathrm{ml}^{-1}$ of blood, whereas at near-maximal exercise capacity this gradient increases to approximately $16 \mathrm{ml} \mathrm{O}_{2} \cdot 100$ $\mathrm{ml}^{-1}$. Thus, the maximal volume of oxygen uptake ( $\mathrm{VO}_{2}$ max $)$ represents the maximal amount of oxygen transported and utilized during aerobic metabolism. ${ }^{11,13}$ Related to pectus excavatum patients, the impairment of one or more components in this equation results in decreased exercise tolerance. It should be noted, however, that $\stackrel{s}{V} \mathrm{O}_{2}$ max can be influenced by various other factors, such as age, gender, and habitual exercise history. ${ }^{7,22-25}$ Also, direct and indirect measurements of $\mathrm{SV}$, EDV, ESV, and $\mathrm{C}_{(a-\bar{v})} \mathrm{O}_{2}$ are possible; however, these procedures often require specialized equipment, are impractical, and do not offer the same advantages as CPET. Therefore, the examination of gas exchange indices measured at the mouth via a two-way breathing valve and metabolic cart provides a more practical alternative that is easily tolerable with healthy and clinical populations. ${ }^{11}$

$$
\begin{gathered}
\dot{V} O_{2}=(\dot{Q}) \cdot C_{(a-\bar{v})} O_{2} \\
\dot{V} O_{2}=\left(f_{c} \cdot S V\right) \cdot C_{(a-\bar{v})} O_{2} \\
\dot{V} O_{2}=\left(f_{c}\right) \cdot(E D V-E S V) \cdot C_{(a-\bar{v})} O_{2}
\end{gathered}
$$

Figure 3 - The Fick equation for calculating oxygen uptake $\left(\mathrm{VO}_{2}\right)$. Refer to text for detailed discussion. $Q$ is cardiac output; $\mathrm{C}_{(a-\bar{v})} \mathrm{O}_{2}$ is the difference between the oxygen content of the arterial $\left(\approx 20 \mathrm{ml}\right.$ of $\mathrm{O}_{2} \mathrm{~mL} \mathrm{O}_{2} \cdot 100 \mathrm{~mL}^{-1}$ of blood) and venous sides; $f$ is cardiac frequency; $\mathrm{SV}$ is stroke volume; $\mathrm{EDV}$ is end-diastolic volume; and ESV is end-systolic volume

The following sections are guidelines for assessing pectus excavatum patients during CPET. The preparation phase is described, followed by the testing phase and then an interpretation of various physiological indices.

\section{Cardiopulmonary Test (Preparation Phase)}

\section{Documenting Patient's Exercise History}

In order to assess the severity of pectus excavatum, investigators need to document the patient's habitual exercise history. Studies have found that in untrained individuals, $\stackrel{s}{V} \mathrm{O}_{2}$ max can increase as much as $20 \%$ following 12 weeks of endurance training. ${ }^{11,26}$ The adaptations to endurance training, however, will not be retained (i.e., deconditioning) if a minimal level of exercise is not maintained. Studies ${ }^{27-29}$ have shown that seven to eight weeks of deconditioning, in moderately training individuals, resulted in a complete reversal of ${ }^{\mathrm{V}} \mathrm{O}_{2}$ max values. Related to components of the Fick equation, Perhonen et al. ${ }^{30}$ found that after two weeks of bed rest, $Q^{s}$ and $S V$ decreased by $17 \%$ and $25 \%$, respectively, from baseline values. Furthermore, the investigators ${ }^{30}$ reported an $8.0 \%$ decrease in left ventricular volume after six weeks of bed rest, whereas the right ventricular volume decreased by $10 \%$ during the same amount of time. Coyle et al. ${ }^{31}$ hypothesized that the decrease in $S V$ may be linked to the reduction in blood volume and not necessarily decreases in cardiac dimensions. Perhonen et al. ${ }^{32}$ reported, however, that reductions in $S V$ measured in an upright position were "... greater after bed rest than after acute hypovolemia alone..." (p.1856). With regard to $C_{(a-v)} O_{2}$, studies have reported a reduction in the oxygen extraction capabilities of the skeletal muscle, which may be mediated by factors such as capillary density, myoglobin concentration, mitochondria size and density, and oxidative enzymes..$^{27,33}$

When evaluating the pectus excavatum patient preoperatively and postoperatively, investigators need to document the patient's habitual exercise history in order to minimize the confounding effects of deconditioning. This is a critical component of the evaluation process, because in the months following the surgical repair, patients may either reduce their level of physical activity or adopt a sedentary lifestyle in order to prevent displacement of the Adkins strut ${ }^{1}$ or Lorenz metal bar. ${ }^{34}$ Therefore, it is recommended that the mode (i.e., type of exercise performed), frequency (i.e., sessions per week), duration (hours per week), length of time the exercise regimen has been consistently maintained, and intensity of exercise be documented for each patient. Malek and colleagues ${ }^{24,25}$ used the following series of questions to document the habitual exercise history of individuals tested in their laboratory: "What type of exercise do you perform?"; "How many sessions per week do you exercise?"; "How many hours per week do you exercise?; "How long have you consistently, no more than one month without exercise, been 
exercising?; and "Indicate [using the Borg Rating of Perceived Exertion (RPE) 6-20 scale], in general, the intensity at which you perform your exercise regimen.

\section{Subject Preparation}

Before the CPET can begin, a number of procedures must be performed. In their meta-analyses, Malek and colleagues ${ }^{9,10}$ reported that studies varied in their approach to measuring pectus severity. Therefore, in order to compare findings across studies in the future, pectus severity should be assessed using the procedures of Haller et al. ${ }^{5}$ This approach uses the CT scan and provides a more objective method of estimating pectus severity than do other approaches such as the Welch index, ${ }^{35}$ which utilizes lateral chest x-ray. ${ }^{5}$ It should be noted, however, that CT scans are not part of standard assessment procedures for evaluating pectus severity; they may be cost-prohibitive. Nevertheless, investigators should justify this cost in their grant or department budget. In addition, if a complete pulmonary function test has not been conducted, then an abbreviated version should be performed to determine forced expiratory volume in the first second $\left(F E V_{1}\right)$, forced vital capacity $(F V C)$, and maximum voluntary ventilation $(M V V)$ values (see ventilatory response variables section for details). The 12-lead ECG electrodes should be placed in accordance with standard guidelines. ${ }^{15}$ Although there is little information in the literature regarding the patterns of heart rhythm in pectus excavatum patients, we recommend placement of ECG electrodes such that any abnormal rhythms may be documented. Depending on the severity of the pectus excavatum, however, electrode placement may have to be modified (particularly leads $\mathrm{v}_{1}, \mathrm{v}_{2}$ and $\mathrm{v}_{3}$ ) at the discretion of the attending physician and/or exercise physiologist.

\section{Cardiopulmonary Test (Exercise Phase)}

Prior to beginning the CPET, the seat height of the cycle ergometer should be adjusted so that the patient has a slight bend $\left(\approx 5^{\circ}\right)$ in their knees. The handle bars should be adjusted so the patient is not leaning forward but rather has an erect posture. Furthermore, the mouthpiece and breathing valve should be adjusted so that the patient is not struggling to maintain the apparatus in their mouth. The nose clip should be properly placed over the nostrils so that no air is escaping as the patient exhales. Also, the metabolic cart should be calibrated prior to each testing session. The CPET protocol that is recommended includes three minutes of rest (i.e., baseline), followed by three minutes of warm-up at unloaded pedaling (i.e., $0 \mathrm{~W}$ ), and then an incremental (i.e., ramp) increase in power output every minute (15 to $\left.20 \mathrm{~W} \cdot \mathrm{min}^{-1}\right)$ thereafter. ${ }^{6,7,11,12}$ The determination of the ramp rate often depends on the patient's level of physical conditioning and, therefore, should be individualized. For example, a faster ramp rate (i.e., 20 or $25 \mathrm{~W} \cdot \mathrm{min}^{-1}$ ) is appropriate for those individuals who engage in regular endurance exercise, whereas a slower ramp rate (i.e., 10 or $15 \mathrm{~W} \cdot \mathrm{min}^{-1}$ ) may be more appropriate for those individuals who are disabled or sedentary. ${ }^{13}$ The ramp protocol is recommended over a step protocol (i.e., increase in power output every two or three minutes), because the physiological responses are more uniform. ${ }^{36}$ The preferred cycling cadence, in a clinical setting, may range between 60 and $70 \mathrm{rev} \cdot \mathrm{min}^{-1}$. In our experience with pectus excavatum patients, we have found that $60 \mathrm{rev} \cdot \mathrm{min}^{-1}$ is well tolerated across different degrees of severity. ${ }^{6,7}$

The criteria for terminating the CPET may range from absolute (i.e., acute myocardial infarction, sustained ventricular tachycardia, or request to stop by the subject) to relative (i.e., hypertensive response, changes in ST segment depression or elevation, or exercise-induced bundle branch block not distinguishable from ventricular tachycardia) indicators. ${ }^{12,13}$ If, however, none of the above indicators are present, patients should receive strong verbal encouragement in order to achieve the upper limits of their physiological capacity. In our laboratory, ${ }^{7,17,23,24,37,38} \stackrel{s}{\mathrm{~V}} \mathrm{O}_{2} \max$ is considered achieved if two of the following three criteria during the test are met: ${ }^{13,39,40}$ a) $90 \%$ of age-predicted maximum heart rate (i.e., 220-age), b) respiratory exchange ratio $>1.20$, and c) a plateauing of oxygen uptake $\left(\leq 150 \mathrm{~mL} \cdot \mathrm{min}^{-1}\right.$ in $V^{s} O_{2}$ over the last 30 seconds of the test). In addition, $\stackrel{s}{V} \mathrm{O}_{2}$ max is determined by taking the highest ${ }^{\mathrm{S}} \mathrm{O}_{2}$, value in the last 30 seconds of the CPET. It is important to note that the patient be allowed to cool-down following the CPET for as long as they want, with $f_{c}$, blood pressure, and ECG being continually monitored until these indices return to those values observed during warm-up.

\section{Physiological Response Variables and Interpretation}

Due to the lack of consistent physiological variables that are reported in the pectus excavatum literature resulting from CPETs, ${ }^{9,10}$ the following section will focus on aerobic capacity, cardiovascular, ventilatory, and gas exchange responses that should be reported in all future articles when CPET is performed on pectus excavatum patients preoperatively and/or postoperatively. Although each of the four categories can be classified by numerous indices, the physiological variables recommended below are easily obtained from the metabolic cart and require no additional equipment (i.e., blood lactate analyzer). This approach was intentionally designed so that each laboratory can provide 
the same information in their manuscripts without incurring additional cost for specialized equipment and/or personnel. In addition, data from the metabolic cart should be reported using moving averages. Most metabolic carts have a range of sampling options from breath-by-breath to 2-minute averages. We recommend that researchers use a moving average (5- or 8-breath). Myers et al. ${ }^{41}$ reported that 5- and 10-second averages of breath-by-breath data resulted in high variability $\left(\approx 4.5\right.$ and $3.5 \mathrm{~mL} \cdot \mathrm{kg}^{-1} \cdot \mathrm{min}^{-1}$, respectively), whereas moving averages (i.e., 5 - or 8 -breath) resulted in lower variability $(\approx$ 1.7 and $\left.1.6 \mathrm{~mL} \cdot \mathrm{kg}^{-1} \cdot \mathrm{min}^{-1}\right)$. The investigators ${ }^{41}$ concluded that the "...gain in accuracy is attained by using larger samples or averaging breaths. Although 60 -s sampling offers the least variability $\left(\mathrm{SD}=0.08 \mathrm{~mL} \cdot \mathrm{kg}^{-1} \cdot \mathrm{min}^{-1}\right)$, it could be argued that samples this large may be too imprecise for evaluating certain interventions." (p.409).

\section{Aerobic Capacity Response Variables}

The response to exercise is a function of numerous physiological mechanisms. The ability to sustain highintensity exercise is contingent on four aerobic parameters: 1) $\left.{ }^{s} \mathrm{O}_{2} \max ; 2\right)$ the gas exchange threshold (GET), above which there is a sustained increase in blood lactic acid concentration; and 3) work efficiency represented as the slope of $\Delta V^{S} O_{2} / \Delta W^{42}$. It should be noted that the fourth aerobic parameter, the time constant for oxygen uptake kinetics

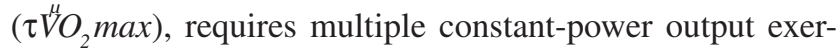
cises, which are performed over a number of visits to the laboratory; ${ }^{43}$ therefore, it is not a practical assessment tool for this population. Thus, we focus our discussion on the first three aerobic parameters.

As discussed earlier, $\stackrel{s}{\mathrm{~V}} \mathrm{O}_{2} \max$ is a measure of aerobic power and should be reported in both absolute $\left(\mathrm{L} \cdot \mathrm{min}^{-1}\right)$ and relative $\left(\mathrm{mL} \cdot \mathrm{kg}^{-1} \cdot \mathrm{min}^{-1}\right)$ terms. The normalization of ${ }^{s} \mathrm{O}_{2}$ max to body weight in kilograms allows the researcher to compare the patient's $\mathrm{VO}_{2}$ max to normative data as well as other pectus excavatum patients within a sample and across studies. In addition, the patient's $\stackrel{s}{V} \mathrm{O}_{2} \max$ value should be reported as a percentage of their predicted $\stackrel{s}{V} \mathrm{O}_{2} \max$. Although there are numerous $\stackrel{s}{V} \mathrm{O}_{2}$ max prediction equations in the literature, we recommend that investigators use the equations by Cooper and Storer, ${ }^{12}$ because these were derived from a composite of five to six prediction equations that included a wide range of clinical populations as well as sedentary to mildly active individuals:

$\stackrel{s}{V} O_{2} \max \mathrm{L} \cdot \min ^{-1}=((0.0716 * \mathrm{ht})-0.0518) *(44.22-$ $(0.394 *$ age $))+(0.0058 * \mathrm{ABW})$ [men]

$\stackrel{s}{V} O_{2} \max \mathrm{L} \cdot \mathrm{min}^{-1}=((0.0626 * \mathrm{ht})-0.0455) *(37.03-$ $(0.371 *$ age $))+(0.0058 * \mathrm{ABW})$ [women] where $h t$ is the patient's height in meters, age is measured in years, and $A B W$ is the actual body weight of the patient in kilograms. The equations of Cooper and Storer, ${ }^{12}$ however, are not appropriate to predict $\stackrel{s}{V} \mathrm{O}_{2} \max$ for aerobically trained individuals/patients, which Malek et al. ${ }^{24,37}$ operationally defined as "... [individuals] who had participated in continuous aerobic exercise three or more sessions per week for a minimum of one hour per session, for at least the past 18 months." Therefore, in such cases, the following equations by Malek et al. ${ }^{24,37}$ should be used to predict ${ }^{s} O_{2}$ max in aerobically trained pectus excavatum patients:

$\stackrel{s}{V} \mathrm{O}_{2} \max \mathrm{mL} \cdot \mathrm{min}^{-1}=27.387(\mathrm{wt})+26.634(\mathrm{ht})-27.572($ age $)+$ $26.161(\mathrm{HPW})+114.904(\mathrm{INT})+506.752(\mathrm{YRT})-4609.791$

[men]

$\stackrel{s}{V} \mathrm{O}_{2} \max \mathrm{mL} \cdot \mathrm{min}^{-1}=18.528(\mathrm{wt})+11.993(\mathrm{ht})-17.197($ age $)+$ $23.522(\mathrm{HPW})+62.118(\mathrm{INT})+278.262($ YRT $)-1375.878$

[women]

where $w t$ is the patient's weight in kilograms, $h t$ is the patient's height in meters, age is measured in years, HPW is the hours per week of training, INT is the overall intensity of each training session as measured by the Borg RPE (6-20) scale, and YRT is the natural log of years of training. Regardless of which prediction equation is used, the researcher should also report the pectus excavatum patient's ${ }^{5} \mathrm{O}_{2}$ max relative to the percentage of the predicted value (i.e., \% predict. $\stackrel{s}{\mathrm{~V}} \mathrm{O}_{2} \max =\left[\right.$ observed $\stackrel{5}{\mathrm{~V}} \mathrm{O}_{2} \max /$ predicted $\left.\left.{ }^{S} O_{2} \max \right] \times 100\right)$.

The GET is also known as the lactate acidosis threshold, or ventilatory threshold, but these terms are essentially used to describe the disproportionate increase in $\mathrm{CO}_{2}$ output relative to oxygen uptake resulting from an accelerated reliance on glycolysis for energy production during incremental exercise ${ }^{11,12}$. The GET has been used to identify an individual's level of aerobic fitness in clinical ${ }^{44,45}$ and sports ${ }^{46,47}$ related settings, as well as for monitoring training adaptations. ${ }^{22}$ The GET is determined through the V-slope method $^{48}$ by using either regression analysis or visual inspection by trained personnel. Briefly, as shown in Figure 4, $\stackrel{s}{\mathrm{~V}} \mathrm{O}_{2}$ and $\stackrel{s}{\mathrm{~V}} \mathrm{CO}_{2}$ increase proportionately at the beginning of incremental exercise, thus yielding a linear slope. As the exercise bout continues, a second slope develops due to the disproportionate increase in $\mathrm{CO}_{2}$ output relative to oxygen uptake. ${ }^{11,13}$ However, because of the potential of acute hyperventilation, it is recommended that the V-slope method be used in conjunction with analyses of the ventilatory equivalents (i.e., $V_{E}^{s} / V^{s} O_{2}$ and $\left.V_{E}^{s} / V^{s} C O_{2}\right)$ and end-tidal gas tensions (i.e., $\mathrm{P}_{\mathrm{ET}} \mathrm{O}_{2}$ and $\mathrm{P}_{\mathrm{ET}} \mathrm{CO}_{2}$ ) for oxygen and carbon dioxide [for a detailed discussion refer to Wasserman et al. ${ }^{11}$ ]. 


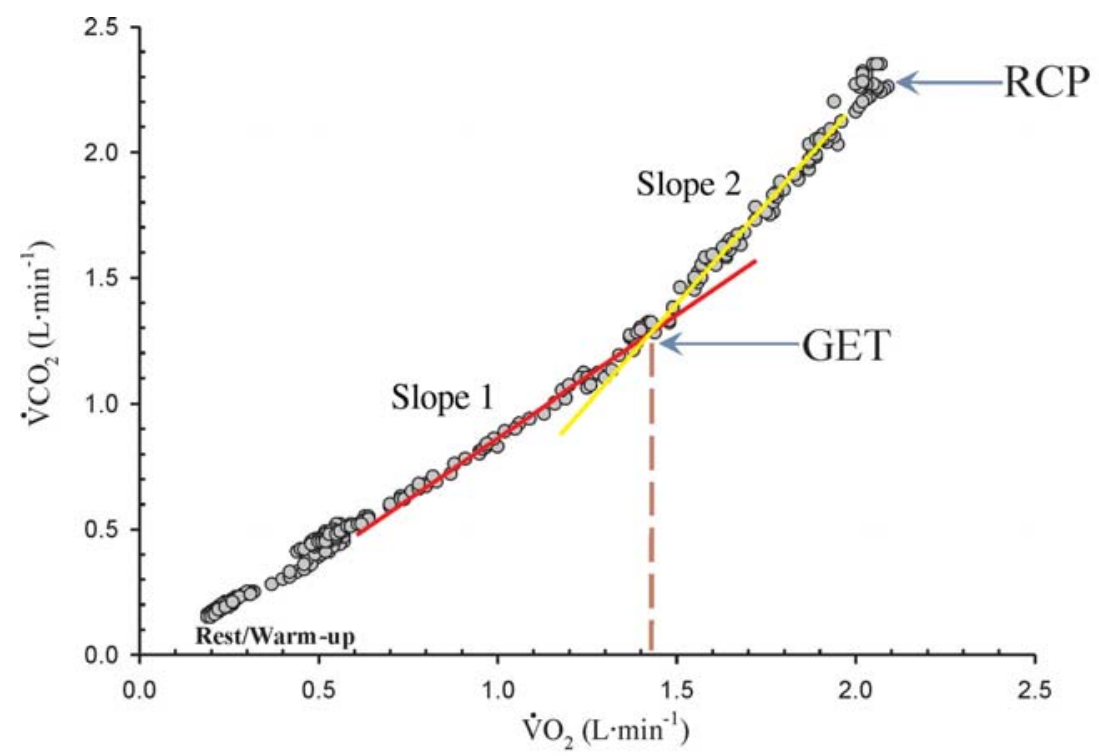

Figure 4 - Determination of GET by V-slope method $\left(\dot{V} \mathrm{CO}_{2} / \dot{V} \mathrm{O}_{2}\right)$ following completion of a CPET. Note: Rest and warm-up data, as well as data points above the respiratory compensation point (RCP), are not to be included in the regression analyses for the determination of the observed GET

Gaskill et al. ${ }^{49}$ recently reported that determining the GET using a combination of the V-slope, ventilatory equivalents, and end-tidal gas tensions methods was more reliable than using any of these methods separately. The GET values should be reported in terms of oxygen uptake similar to the $\stackrel{s}{V} \mathrm{O}_{2}$ max values (i.e., $\mathrm{L} \cdot \mathrm{min}^{-1}$ and $\mathrm{mL} \cdot \mathrm{kg}^{-1} \cdot \mathrm{min}^{-1}$ ) as well as a percentage of the predicted ${ }^{s} \mathrm{O}_{2} \max$ (i.e., \%pred ${ }_{V O_{2 \max }}^{s}=$ [measured GET / predicted $\mathrm{V}_{2} \mathrm{O}_{2}$ max] x 100). ${ }^{12}$ It is recommended that the predicted ${ }^{S} O_{2}$ max value be used, and not the measured $\stackrel{s}{V} \mathrm{O}_{2} \max$ value, because the "...measured ${ }^{\mathrm{S}} \mathrm{O}_{2}$ max can produce serious errors of interpretation in the case of a suboptimal effort..." (p.103), ${ }^{12}$ which is more likely in clinical settings. Typically, in healthy individuals, the \% pred $_{V O_{2 \max }}^{s}$ for GET occurs at $50 \%$ to $60 \%$, whereas in diseased populations, this value is often equal to or less than $40 \% .^{12}$ For example, Malek et al. ${ }^{7}$ reported that physically active pectus excavatum patients with a severity index greater than 5.0 had GET values $\leq 39 \%$. Thus, investigators can use \% pred $_{V^{\prime} O_{2 \max }}$ to characterize the level of conditioning in their sample, which may provide insight into the patient's muscle energetics.

The measure of work efficiency, $\Delta V^{s} O_{2} / \Delta W$, is independent of gender, age, or height and has a consistency for apparently healthy subjects, being $10.3 \mathrm{~mL} \cdot \mathrm{min}^{-1} \cdot \mathrm{W}^{-1}(\mathrm{SD}=$ $1.0 \mathrm{~mL} \cdot \mathrm{min}^{-1} \cdot \mathrm{W}^{-1}$ ) with a $95 \%$ confidence interval of 8.3 to $12.3 \mathrm{~mL} \cdot \mathrm{min}^{-1} \cdot \mathrm{W}^{-1} \cdot{ }^{12,13}$ The $\Delta V^{s} O_{2} / \Delta W^{s}$ examines the oxygen utilization by the skeletal muscles in their performance of work. Poole et al..$^{50}$ found that the $\Delta V_{2}^{s} O_{2} / \Delta W_{W}^{S}$ calculated from pulmonary gas exchange measurements and that measured directly from the leg (i.e., constant-infusion thermodilution) had similar values $\left(9.9\right.$ vs. $\left.9.2 \mathrm{~mL} \cdot \mathrm{min}^{-1} \cdot \mathrm{W}^{-1}\right)$. Therefore, the investigators ${ }^{50}$ concluded that $\Delta V^{s} O_{2} / \Delta W^{S}$ represents the muscular efficiency of the exercising limb. A reduction in $\Delta \stackrel{s}{V}_{2} / \Delta W^{S}$ may indicate inadequacies with factors related to oxygen transport [for a detailed review, refer to citation $33]$.

\section{Cardiovascular Response Variables}

\section{Heart Rate $\left(f_{c}\right)$ and Cardiac Reserve}

The cardiovascular response to incremental exercise is one potential limitation to exercise tolerance. ${ }^{11}$ In pectus excavatum patients, the assessment of cardiovascular variables can provide valuable information related to the efficiency of surgical repair as well as the patient's response to maximal exercise. Some researchers have used the predicted $f_{c}$ max as a marker for achieving the upper-limits of exercise tolerance, and thus terminate the CPET on this basis. It is well-agreed in the exercise physiology literature that this approach is inappropriate because of the variances associated with the available prediction equations for $f_{c}$ max. ${ }^{16}$ Despite this drawback, however, the patient's $f_{c} \max$ relative to their predicted value should be reported. Typically, one of two prediction equations are used to estimate a $f_{c} \max$ : 1) 220-age or 2) 210-(age x 0.65). ${ }^{11,12}$ Regardless of which equation is used to estimate $f_{c} \max$, investigators should report the mean and standard deviation of the actual $f_{c} \max$ and the percentage of predicted (i.e., [actual $f_{c} \max /$ predicted $\left.\left.f_{c} \max \right] \times 100\right)$ for their sample. In addition to reporting $f_{c} \max$, the resting $f_{c}$ value, which is recorded during the baseline phase of the CPET, should also be reported by the investigator. 
Related to $f_{c}$ max is cardiac reserve, defined as the difference between the measured and predicted $f_{c} \max$ values. This information can be used to determine whether the subject achieved cardiovascular limitation. As a general rule, a small cardiac reserve value and a high ventilatory reserve value (discussed below) indicates cardiovascular limitation to incremental exercise. ${ }^{11,12}$

\section{Oxygen Pulse ( $\left.\mathrm{VO}_{2} \max / f_{c} \max \right)$}

Due to the close relationship between $f_{c}$ and ${ }^{s} \mathrm{O}_{2}$ (Figure 3), the slope of the $f_{c} / \dot{V} O_{2}$ relationship can provide information related to the patient's level of cardiovascular conditioning. $\Delta f_{c} / \Delta V^{s} O_{2}$ is the slope of the relationship between heart rate and $\mathrm{VO}_{2}$ during incremental exercise. This slope is related both to stroke volume and to the difference in oxygen content between arterial and mixed venous blood $^{11-13} . \Delta f_{c} / \Delta V^{s} O_{2}$ is also the reciprocal of the asymptotic oxygen pulse $\left(\mathrm{VO}_{2} / f_{c}\right)$, which is a measure of cardiovascular efficiency with units of milliliters per beat. ${ }^{11-13}$ Thus, $V_{2}^{s} O_{2} / f_{c}$ is closely related to $S V$ and may be used to estimate $S V$ at various stages of incremental exercise testing. ${ }^{11-13}$

\section{Ventilatory Response Variables}

The examination of ventilatory indices during incremental CPET provides information related to the pectus excavatum patient's pulmonary function. Previous studies have found that values for pulmonary function indices, such as FEVI, $F V C$, and $M V V$, are in the low normal range and that pectus excavatum does not influence the patient's overall pulmonary function..$^{67,10,51-53}$ (For a detailed review of the effects of pectus excavatum on pulmonary function, refer to citation 10). Because pulmonary function tests are effort-dependent, it is recommended that the patient perform several trials with strong verbal encouragement from the pulmonary technician. For detailed guidelines regarding pulmonary function testing, refer to citation. ${ }^{54}$ Consistent with these findings, Malek et al. ${ }^{10}$ found a small mean-weighted effect size (ES $=0.07, P$ $>0.05$ ) for pulmonary function following surgical repair, but noted that many of the indices were measured at rest and not during exercise. It is well-established in the clinical exercise physiology literature that examination of ventilatory function during CPET is equally as important in patient assessment as cardiovascular function. ${ }^{11-13,55}$ Therefore, future studies should examine and report the following ventilatory responses to CPET in order to more accurately assess the potential impairment of pectus excavatum on pulmonary function.

\section{Minute Ventilation $\left(\stackrel{s}{V}_{E}\right)$}

At rest, breathing frequency $\left(f_{R}\right)$ in healthy individuals is approximately 12 to 15 beats $\cdot \mathrm{min}^{-1}$, whereas tidal volume
$\left(V_{T}\right)$ is 0.500 liters. Minute ventilation $\left(V_{E}^{S}\right)$ is thus the product of $f_{R}$ and $V_{T}$ and is typically $6.0 \mathrm{~L} \cdot \mathrm{min}^{-1}$ at rest. However, during vigorous exercise $f_{R}$ and $V_{T}$ increase to 50 beats $\cdot \mathrm{min}^{-1}$ and $3.0 \mathrm{~L} \cdot \mathrm{min}^{-1}$, respectively, resulting in a $V_{E}^{s}$ of $150 \mathrm{~L} \cdot \mathrm{min}^{-1}$. It should be noted, however, that during low-intensity exercise, $V_{T}$ primarily increases, whereas during higher-intensity exercise (i.e., $80 \%$ of $\stackrel{s}{V} O_{2} \max$ ), both $V_{T}$ and $f_{R}$ increase, with only $f_{R}$ increasing as the individual approaches $\mathrm{VO}_{2} \max { }^{11-13}$ $V_{E}^{s}$ is a critical component of regulating acid-base balance during increased metabolic demands by the exercising muscles. ${ }^{11-13}$ During the CPET, the relationship between $\mathrm{CO}_{2}$ output and $V_{E}^{s}$ is mostly linear, up to approximately 85 to $90 \%$ of ${ }^{S} O_{2}$ max. $^{11-13}$ Thereafter, $V_{E}^{s}$ increases disproportionately to $\mathrm{CO}_{2}$ output. This breakpoint is called the respiratory compensation point (RCP). The underlying mechanism of the RCP is related to the stimulation of the peripheral chemoreceptors of the carotid bodies.

\section{Ventilatory Reserve}

To evaluate whether the patient exhibited ventilatory limitation to exercise, the researcher should compare the

Table 1 - Step-by-step approach for CPET of pectus excavatum patients

\section{Preparation Phase}

- Document patients' exercise history using questions outlined in the text.

\section{Subject Preparation}

- Use of CT scan to estimate Haller pectus severity index.

- At a minimum, measure $F E V_{l}, F V C$, and $M V V$ at part of pulmonary function test.

-Place ECG electrodes.

\section{Exercise Phase}

- Ensure cycle ergometer, subject, breathing valve, and metabolic cart are appropriately set up.

\section{Aerobic capacity response variables}

- Report $V_{2} \max \left(\mathrm{L} \cdot \mathrm{min}^{-1}\right.$ and $\left.\mathrm{mL} \cdot \mathrm{kg}^{-1} \cdot \mathrm{min}^{-1}\right)$ and as a percentage of predicted $\mathrm{VO}_{2}$ max.

- Estimate GET using the V-slope method and report value in terms of V $O_{2}\left(\mathrm{~L} \cdot \mathrm{min}^{-1}\right.$ and $\left.\mathrm{mL} \cdot \mathrm{kg}^{-1} \cdot \mathrm{min}^{-1}\right)$, as well as a percentage of

predicted $\stackrel{\mathrm{V}}{\mathrm{O}_{2}} \max$

- Report work efficiency $\left(\Delta \dot{V} \mathrm{O}_{2} / \Delta W\right)$.

Cardiovascular response variables

- Report resting heart rate $\left(f_{c}\right)$ as well as $f_{c}$ at $V_{2} O_{2} \max \left(\right.$ i.e., $f_{c} \max$ ).

- Report cardiac reserve (i.e., $f_{c} \max$ - predicted $f_{c} \max$ ).

\section{Ventilatory response variables}

- Report minute ventilation at $\mathrm{VO}_{2} \max \left(\right.$ i.e., $\left.V_{E} \max , \mathrm{L} \cdot \mathrm{min}^{-1}\right)$ as a percentage of MVV.

- Report ventilatory reserve (i.e., measured MVV - $V_{E}$ max).

Note: Refer to text for discussion of each variable and procedure. 
$V_{E}^{s} \max$ value attained at ${ }^{s} \mathrm{O}_{2} \max$ as a percentage of the patient's $M V V$ value (i.e., $\left.\% M V V=\left[V_{E}^{s} \max / M V V\right] \times 100\right)$. In healthy individuals, the $\% M V V$ at $V O_{2} \max$ is approximately $50-70 \%,{ }^{11-13}$ whereas in patients with respiratory disease (e.g., COPD), this value may be greater than $80 \% .^{11,56,57}$ Johnson et al. ${ }^{58}$ reported that, in healthy individuals, the $V_{E}^{s} \max$ achieved at maximal exercise capacity was highly correlated with the measured $M V V$. In order to better understand the physiological limitation of pectus excavatum to exercise, future studies should report the $\% M V V$ value for their sample in addition to the $\vec{V}_{E} \max$ and $M V V$ values.

\section{CONCLUSION}

In summary, Table 1 provides a step-by-step approach that should be used when assessing cardiopulmonary responses in a pectus excavatum patient before and after surgical repair. Although investigators are encouraged to use other laboratory techniques to assess the effects of pectus excavatum on cardiovascular and pulmonary function, it is imperative that, at a minimum, they conduct a CPET as outlined above and report the corresponding indices.

\section{REFERENCES}

1. Fonkalsrud EW, Dunn JCY, Atkinson JB. Repair of pectus excavatum deformities: 30 years experience with 375 patients. Ann Surg. 2000; 231:443-448

2. Hook EB. Epidemiology of Down Syndrome. In: Pueschel SM, Rynders JE, eds. Down syndrome: Advances in biomedicine and the behavioral sciences. Cambridge: Ware Press. 1982;11-88.

3. Fonkalsrud EW. Chest wall abnormalities. In: Baue AE, Geha AS, Hammond GL, et al., eds. Glenn's thoracic and cardiovascular surgery. Stamford: Appleton and Lange. 1995;581-592.

4. Fonkalsrud EW. Current management of pectus excavatum. World J Surg. 2003;27:502-508

5. Haller JA, Jr., Kramer SS, Lietman SA. Use of CT scans in selection of patients for pectus excavatum surgery: a preliminary report. J Pediatr Surg. 1987;22:904-906.

6. Malek MH, Fonkalsrud EW. Cardiorespiratory outcome after corrective surgery for pectus excavatum: A case study. Med Sci Sports Exerc. 2004; $36: 183-190$

7. Malek MH, Fonkalsrud EW, Cooper CB. Ventilatory and cardiovascular responses to exercise in patients with pectus excavatum. Chest. 2003; 124:870-882.

8. Malek MH, Berger DE, Marelich WD, Coburn JW. On the application of meta-analysis in pectus excavatum research. Am J Cardiol. in press.

9. Malek MH, Berger DE, Housh TJ, Marelich WD, Coburn JW, Beck TW. Cardiovascular function following surgical repair of pectus excavatum: a meta-analysis. Chest. 2006;130:506-16.

10. Malek MH, Berger DE, Marelich WD, Coburn JW, Beck TW, Housh TJ. Pulmonary function following surgical repair of pectus excavatum: a meta-analysis. Eur J Cardiothorac Surg. 2006;30:637-43.
11. Wasserman K, Hansen JE, Sue DY, Stringer WW, Whipp BJ. Principles of exercise testing and interpretation : including pathophysiology and clinical applications. 4th ed. Philadelphia: Lippincott Williams \& Wilkins, 2005.

12. Cooper CB, Storer TW. Exercise testing and interpretation: A practical approach. London: Cambridge University Press, 2001.

13. ATS/ACCP. ATS/ACCP Statement on cardiopulmonary exercise testing. Am J Respir Crit Care Med. 2003;167:211-77.

14. American College of Sports Medicine., Pollock ML, Gaesser GA, Butcher JD, Després J, Dishman RK, Franklin BA, Garber CW. American College of Sports Medicine Position Stand. The recommended quantity and quality of exercise for developing and maintaining cardiorespiratory and muscular fitness, and flexibility in healthy adults. Med Sci Sports Exerc.1998;30:975-91.

15. Fletcher GF, Balady GJ, Amsterdam EA, Chaitman B, Eckel R, Fleg J, Froelicher VF, Leon AS, Pina IL, Rodney R, Simons-Morton DA, Williams MA, Bazzarre T. Exercise standards for testing and training: a statement for healthcare professionals from the American Heart Association. Circulation. 2001;104:1694-740.

16. Myers J. Applications of cardiopulmonary exercise testing in the management of cardiovascular and pulmonary disease. Int J Sports Med. 2005;26:S49-S55.

17. Malek MH, Housh TJ, Schmidt RJ, Coburn JW, Beck TW. Proposed tests for measuring the running velocity at the oxygen consumption $\left(\mathrm{RV}_{\mathrm{VO} 2}\right)$ and heart rate $\left(\mathrm{RV}_{\mathrm{HRT}}\right)$ thresholds for treadmill exercise. J Strength Cond Res. 2005; 19:847-852.

18. Koga S, Shiojiri T, Shibasaki M, Fukuba Y, Fukuoka Y, Kondo N. Kinetics of oxygen uptake and cardiac output at onset of arm exercise. Respir Physiol. 1996;103:195-202. 
19. Richardson RS, Knight DR, Poole DC, Kurdak SS, Hogan MC, Grassi B, Wagner PD. Determinants of maximal exercise $\mathrm{Vo}_{2}$ during single leg knee-extensor exercise in humans. Am J Physiol. 1995;268:H1453-1461.

20. Knight DR, Poole DC, Schaffartzik W, Guy HJ, Prediletto R, Hogan MC, Wagner PD. Relationship between body and leg $\mathrm{Vo}_{2}$ during maximal cycle ergometry. J Appl Physiol. 1992;73:1114-21.

21. Wilmore JH, Costill DL. Physiology of sport and exercise. 3rd ed. Champaign, IL: Human Kinetics, 2004.

22. Jones AM, Carter $\mathrm{H}$. The effect of endurance training on parameters of aerobic fitness. Sports Med. 2000;29:373-86.

23. Malek MH, Berger DE, Housh TJ, Coburn JW, Beck TW. Validity of $\mathrm{Vo}_{2}$ max equations for aerobically trained males and females. Med Sci Sports Exerc. 2004;36:1427-32.

24. Malek MH, Housh TJ, Berger DE, Coburn JW, Beck TW. A new non-exercise based $\mathrm{VO}_{2}$ max prediction equation for aerobically trained females. Med Sci Sports Exerc. 2004;36:1804-10.

25. Malek MH, Housh TJ, Berger DE, Coburn JW, Beck TW. A new nonexercise-based $\mathrm{Vo}_{2}$ max prediction equation for aerobically trained men. J Strength Cond Res. 2005; 19:559-65.

26. Wilmore JH, Stanforth PR, Gagnon J, Leon AS, Rao DC, Skinner JS, Bouchard C. Endurance exercise training has a minimal effect on resting heart rate: the HERITAGE Study. Med Sci Sports Exerc. 1996;28:829-35

27. Wilber RL, Moffatt RJ. Physiological and biochemical consequences of detaining in aerobically trained individuals. J Strength Cond Res. 1994;8:110-24.

28. Fringer MN, Stull GA. Changes in cardiorespiratory parameters during periods of training and detraining in young adult females. Med Sci Sports. 1974;6:20-5.

29. Klausen K, Andersen LB, Pelle I. Adaptive changes in work capacity, skeletal muscle capillization and enzyme levels during training and detraining. Acta Physiol Scand. 1981;113:9-16.

30. Perhonen MA, Franco F, Lane LD, Buckey JC, Blomqvist CG, Zerwekh JE, et al. Cardiac atrophy after bed rest and spaceflight. J Appl Physiol. 2001;91:645-53.

31. Coyle EF, Hemmert MK, Coggan AR. Effects of detraining on cardiovascular response to exercise: Role of blood volume. J Appl Physiol. 1986;60:95-99.

32. Perhonen MA, Zuckerman JH, Levine BD. Deterioration of left ventricular chamber performance after bed rest : "cardiovascular deconditioning" or hypovolemia? Circulation. 2001;103:1851-7.

33. Wagner PD. Determinants of maximal oxygen transport and utilization. Annu Rev Physiol.1996;58:21-50.

34. Park HJ, Lee SY, Lee CS, Youm W, Lee KR. The Nuss procedure for pectus excavatum: evolution of techniques and early results on 322 patients. Ann Thorac Surg. 2004;77:289-95.

35. Welch KJ. Satisfactory surgical correction of pectus excavatum deformity in childhood: A limited opportunity. J Thorac Surg.1958;36:697-713.

36. Myers J, Bellin D. Ramp exercise protocols for clinical and cardiopulmonary exercise testing. Sports Med. 2000;30:23-9.
37. Malek MH, Housh TJ, Coburn JW, Weir JP, Schmidt RJ, Beck TW. The effects of interelectrode distance on electromyographic amplitude and mean power frequency during incremental cycle ergometry. J Neurosci Methods. 2006;151:139-47.

38. Malek MH, Coburn JW, Weir JP, Beck TW, Housh TJ. The effects of innervation zone on electromyographic amplitude and mean power frequency during incremental cycle ergometry. J Neurosci Methods. 2006;155:126-33.

39. Baumgartner TA, Jackson AS. Measurement for evaluation in physical education and exercise science. 7th ed. Boston: WCB/McGraw-Hill, 2003.

40. Day JR, Rossiter HB, Coats EM, Skasick A, Whipp BJ. The maximally attainable VO2 during exercise in humans: The peak vs. maximum issue. J Appl Physiol. 2003;95:1901-7.

41. Myers J, Walsh D, Sullivan M, Froelicher V. Effect of sampling on variability and plateau in oxygen uptake. J Appl Physiol. 1990;68:404-10

42. Whipp BJ, Davis JA, Torres F, Wasserman K. A test to determine parameters of aerobic function during exercise. J Appl Physiol.1981;50:217-21.

43. Jones AM, Poole DC. Oxygen uptake kinetics in sport, exercise and medicine : a practical handbook. New York: Routledge, 2005.

44. Tesiorowski AM, Harris M, Chan KJ, Thompson CR, Montaner JS. Anaerobic threshold and random venous lactate levels among HIVpositive patients on antiretroviral therapy. J Acquir Immune Defic Syndr. 2002;31:250-1.

45. Thin AG, Linnane SJ, McKone EF, Freaney R, FitzGerald MX, Gallagher CG, et al. Use of the gas exchange threshold to noninvasively determine the lactate threshold in patients with cystic fibrosis. Chest. 2002;121:1761-70

46. Maffulli N, Testa V, Capasso G. Anaerobic threshold determination in master endurance runners. J Sports Med Phys Fitness. 1994;34:242-9.

47. Tanaka K, Matsuura Y. Marathon performance, anaerobic threshold, and onset of blood lactate accumulation. J Appl Physiol.1984;57:640-3.

48. Beaver WL, Wasserman K, Whipp BJ. A new method for detecting anaerobic threshold by gas exchange. J Appl Physiol. 1986;60:2020-7.

49. Gaskill SE, Ruby BC, Walker AJ, Sanchez OA, Serfass RC, Leon AS. Validity and reliability of combining three methods to determine ventilatory threshold. Med Sci Sports Exerc. 2001;33:1841-8.

50. Poole DC, Gaesser GA, Hogan MC, Knight DR, Wagner PD. Pulmonary and leg $\mathrm{VO}_{2}$ during submaximal exercise: implications for muscular efficiency. J Appl Physiol. 1992;72:805-10.

51. Kaguraoka H, Ohnuki T, Itaoka T, Kei J, Yokoyama M, Nitta S. Degree of severity of pectus excavatum and pulmonary function in preoperative and postoperative periods. J Thorac Cardiovasc Surg. 1992;104:1483-8.

52. Kowalewski J, Barcikowski S, Brocki M. Cardiorespiratory function before and after operation for pectus excavatum: Medium-term results. Eur J Thorac Cardiovasc Surg. 1998;13:275-9.

53. Morshuis W, Folgering H, Barentsz J, van Lier H, Lacquet L. Pulmonary function before surgery for pectus excavatum and at long-term followup. Chest. 1994;105:1646-52. 
54. Miller MR, Hankinson J, Brusasco V, Burgos F, Casaburi R, Coates A, et al. Standardisation of spirometry. Eur Respir J. 2005;26:319-338.

55. Poole DC, Richardson RS. Determinants of oxygen uptake: Implications for exercise testing. Sports Med. 1997;24:308-320

56. Montes de Oca M, Rassulo J, Celli BR. Respiratory muscle and cardiopulmonary function during exercise in very severe COPD. Am J Respir Crit Care Med, 1996;154:1284-1289
57. Bauerle O, Younes M. Role of ventilatory response to exercise in determining exercise capacity in COPD. J Appl Physiol. 1995; 79:1870-7.

58. Johnson BD, Scanton PD, Beck KC. Regulation of ventilatory capacity during exercise in .asthmatics. J Appl Physiol.1995;79:892-901.

59 Fonkalsrud EW, Beanes S, Hebra A, Adamson W, Tagge E. Comparison of minimally invasive and modified Ravitch pectus excavatum repair. J Pediatr Surg. 2002;37:413-7. 